\title{
For the beauty of our globe
}

\author{
F.M. Riegler
}

Published online: 27 February 2015

(C) Springer-Verlag Wien 2015

\section{Dear reader,}

The length of the editorial in this issue of European Surgery is considered to be justified by the current changes within the health and medical systems in Central Europe. It seems that reflection is necessary to be prepared and ready for the future developments. As a matter of fact, tables are turning. Save your seat or look out for an alternative. The consequences of this necessary "revolution" for the patients, nursing personnel, and the physicians remain to be explored.

First of all, this issue of European Surgery incorporates reports on studies proving the advantage of specialization and focus. The spectrum ranges from surgical treatment of functional benign disorders $[1,2]$ to the management of oncologic diseases [3]. Going in line with the conclusion of the authors, the benefit of specialization is profoundly improved by the inclusion of a multidisciplinary approach. Thus, the manager of health-and not that of disease-orchestrates the work of the specialists to generate a well-tuned symphony of actions to re-establish and maintain life quality, well-being, and productivity of the patients. Beyond that, we may look out for a better understanding regarding the pathogenesis of a disease and why so many disorders share a common ground. Therefore, the group around the highly trusted and open-minded surgeon Alexander Simic from Belgrade addresses a topic with major relevance, practicality, and importance [4]. In their article, the authors discuss that different surgical diseases may be drawn back to a common ground, i.e., herniosis, and this observation may reveal a taste of truth regarding the development of mal-

F. M. Riegler $(\square)$

Reflux Medical,

Mariannengasse 10/9,

1090 Vienna, Austria

e-mail: martin.riegler@refluxmedical.com adies. I deeply hope that you share my enthusiasm for these articles.

Feel free to skip the rest of this editorial and return to these concepts later, whenever you may find the time to do so; I promise that it definitely is all about YOU, as the center and modulator of YOUR world, irrespective of your specialty, likes, and know-hows. Let us clear up before we power out.

\section{Power of the multidisciplinary approach}

Going in line with the topic of the articles in the present issue of European Surgery, I wish to draw your attention to an upcoming scientific meeting on the multidisciplinary approach for the management of gastroesophageal reflux disease (GERD) and Barrett's esophagus (Vienna, June 12th, 2015) [5]. The program will be presented in German language and is designed by the well-known group around the academic upper gastrointestinal surgeon Sebastian F. Schoppmann (Upper Gastrointestinal Research \& Service, Medical University Vienna, Comprehensive Cancer Center; MUW CCC). Based on the local and international reputation of the group, the meeting, entitled "Reflux multidisziplinär," will update the entire spectrum from diagnoses to therapies of GERD and Barrett's esophagus. Well-selected specialists will contribute to assure the high quality of the meeting [5]. Further information on the meeting is given within this issue of European Surgery.

\section{Power of mood}

Please excuse this digression: life is based on assumptions. Assumption 1: if two individuals see a same thing (i.e., an anatomical structure), they see it in the same way (color, form, etc.) as the same thing (fat, muscle, 
mucosa, etc.). Proof: otherwise, education regarding the identification and handling of anatomical structures during surgery or histopathology would not be possible. Assumption 2: assumption 1 is false. The reason why surgery team work works depends on mechanisms that are not covered by the artificial lingual replacement of truth and false. Assumption 3: it is impossible to verify the truth of the above assumptions. Thus, true and false, right and wrong, good and bad, etc., simply serve as the justification of our actions (logic and morals decide, but do not explain). Assumption 4: statements on perceptions are generated in our brain or elsewhere (?) without having a representation in the so-called outer world (whatever this may be). Proof: the truth of none of the above assumptions is possible, and thus truth and false, good and bad, right and wrong as absolute measures may not exist. But they are important for the approximation required for logos-based life of man (homo google sapiens spider technicus absolutus). This is a great and fundamental day for the fisher man: again, man got caught in the net! It seems that essential reasoning does not always work for the so-called normal life. Why then bother with these issues? It seems, at least before leaving our current state of being (life), we will be enlightened and commence to understand it all, as all becomes clear at the end. Again, we learn that this statement also serves as a model, and may be far off what really happens. Out of the circuit dances the laughing devil: oracle fills the whole. And here we go within the extended herniation from the known to the unknown.

If there exists any truth, it is the power of mood, the fundamental universal and unique driving force and continuous process energy of any change out of the lack limos deficit attractor of matter, mind, and thought. Why do things appear to be in motion? Why do things move and groove? Maybe that they HAVE to move as a MUST in order to find a state of energy that they do not get at another "location" within the colorful spectrum of space and time? Maybe change is a must driven out of the limos [6, 7]? Here we see that lack limos deficit (LLD) fosters change, motion, and continuity of spectral evolution: lack limos beyond the neutron, electron, positron energy, states of matter, and mood $[6,7]$ ? What matters is the power of mood (Fig. 1).

Computed tomography (CT) scan, magnetic resonance imaging (MRI), positron emission tomography (PET) scan: open your eyes and look within; noises upon irregular scheme-like line following readings in between the circuits of your thoughts; through shine rules the light (Fig. 2). A fat person is not obese; he or she simply offers a larger area for pure sun light reflection. Bariatrics should have this in mind before doing their minimally invasive procedures including rings, balloons, staples, and slings. The camera takes it all. Laparoscopy rules the scene, takes the lead within the theme and does not fit into the song for taking the history of the patients. We are surgeons; we want to cut, order, rearrange, and cure with our HANDS. Here a hero surgeon states: let the internal medicine crocodile power game rockers take the history

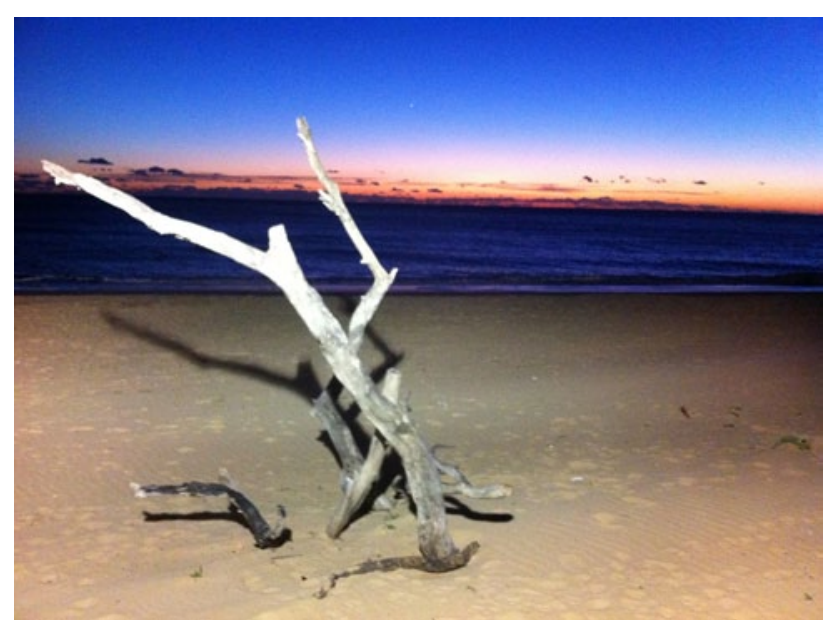

Fig. 1 The image mirrors the idea of the outstanding power of mood, as described in the text

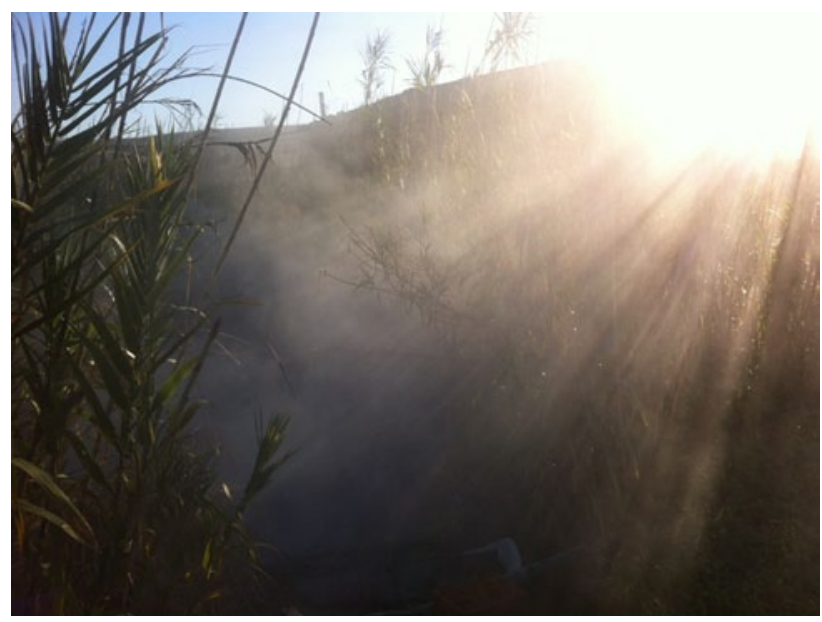

Fig. 2 The image mirrors the idea that through shine rules the light, as described in the text

of the patients. We are the heroes, they are the spiders. And as we are baldhead heroes, we are the real surgeons. We cut the net of the spiders into little pieces, without knowing that we definitely cut ourselves. The more we cut, the more we get lonely, abandoned, and extruded from our families, friends, and colleagues. Some of us are even thrown out of the home, house, and get divorced. This is the price of the hero for the unique manifestation of the obsession from thorax to the abdomen, from heart to aorta, from skin to bone, from teeth to throne, from eye to anus. There is no excuse: who cares, we are heroes! Numbers count; the more the better; the higher the volume, the better the reputation and self-esteem of the surgeon, and it all takes place within the power of mood. Heroes pretend to live in paradise; in fact, they live within a dessert of hate, greed, and envy. Others drank the water at the cost of the hero. What remains is a handful grain of sand.

The process starts with the diagnosis. The ignorance for the important pretreatment diagnostic nonmachine 
(i.e., CT MRI scan, endoscopy) test-dependent communication fosters the surgeon to get cut off from the essence of the art of medicine. Reaction replaces the conduct of reasoning. It seems that the only motion that counts is the motion of dollar-euro volumes into the individual electronic bank account. And where are we? Where do the human beings stand with their outstanding and exclusive spider capacity of oral language-based communication? Have we given up and cut off ourselves from the logos? Heroes replace the gods, absence replaces presence. Lack limos fills the stage [6, 7]. We measure what we know. Children are excited about heroes. Children love heroes (Fig. 3). Patients are angels. Let them fly in for the benefit of the Excel list-driven count down of our society. Since ever, Africa hides the fire of the world [8]. Asia blows out the desert-drunk ice winds toward Europe, the old sick stolen woman peninsula along the Mediterranean sea [9]. Legacy tells that water falls, rivers turn, bridges break, and soil hides, nourishes, and reveals. Here we talk about the orchestration of the perception under the power of mood.

\section{Power of mind}

Conceptually, truth serves as the moral justification of your action. As a consequence, your reasoning is considered to be based on the rules of logic. Well taken! In contrast to that, there are perceptions that we know, those that we do not know, and those that we have forgotten, of which some may return back into our knowledge and remembrance playing history. Even the statement "knowledge represents the interpretation of the individual tune of mood" cannot be true, as it simply serves to justify the lack limos of truth [6]. This is why you may

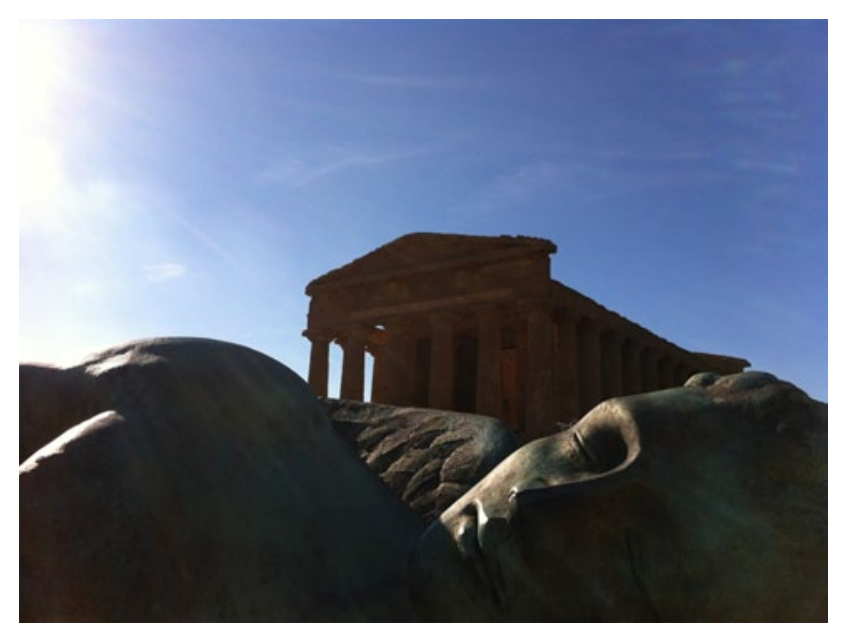

Fig. 3 The image mirrors the archaic idea that heroes serve to communicate between gods and man. This communication develops against the background of the cosmic understanding of the universe, as depicted by the harmonic orchestration of the Greek temple depicted in the back of the image. (Image obtained in Agrigento, Sicily, Italy, EU) come up with the conclusion that truth does not exist, why reasoning cannot think being, and why reasoning and being essentially represent the same. Rock around the clock with Parmenides bills the hilly pay of pale, as the moon comes down to swallow itself as the Chandrasoma fell and came back to time out space and life. Out of the limos it all falls into being and exists. This is the real motive for the moon shine serenade [10]. If we accept these thoughts, things are, are not, or are forgotten, which in fact makes no difference and remains to be the same. Thus, birth and death are the only "forgotten" manifestations of energy. Going in line with this notion, we have to be very careful with our actions.

Usually, diagnosis serves to justify treatment. The more objective criteria are applied, the closer we come to the point to reveal that a certain treatment is suggested to foster return to health. Economy-driven diagnosis is frequently conducted and simply serves to justify an expensive treatment that in turn serves the medical and pharmaceutical industry and to increase the income of the physician. This conduct of logical reasoning explains why morals remain to be the tears running over the cheeks of the so-called humanism. Even humility may serve as the justification to adore AND serve the other side of the coin: despotism tunes always and everywhere. At least it is the despotism of YOUR stream of mood, the manifestation of YOUR power of mood. Energy alters to foster the change of drive. But does it make a difference, if you are, hate, cheat, kill, and chill, using words of the ancient Greek or Latin language? Humanism represents a Roman type recall of the past, which forgot how colorful temples have been designed to orchestrate the harmony of life, peace, war, being, and time. And what about today? Translation of mood does not work in the form of language; it remains the power of sound and music. Nowadays, English replaces Latin at least in the medical arena: Captain, I have to overemphasize with overwhelming adoration for the "How are you? (but I do not care how you are), show me your data, publish or perish, great job, awesome, we thank you brother George, for what you have done to the globe, you released what Einstein has been calculating: the power of mood has been transferred into the massively ejaculating power of arms, rest there in peace." Mr. Heraclitus profoundly cares about lightning: "relativity leads difference into flow." And since there exists no English term to express and translate a state of mood energy indicating Viennese "Gemütlichkeit," "Schmäh-Bankerl," and "gnädige Frau," the etymologic gap between different languages causes the lack limos of emotion, thinking, and reasoning. As a consequence, the above terms do not find a representation in the new modern world of today. Lack of word indicates lack limos of a given semiotic and semantic color [6, 7]. Why not going back to the essence of our so-called roots and talk, take histories, and consider the "truth" in between the lines, words, and sayings. Music is the universal language. Roots do not only shine where the soil is taken away, where Rastas grow their dread lock hairs, since they have thrown the comb away. There it lies 


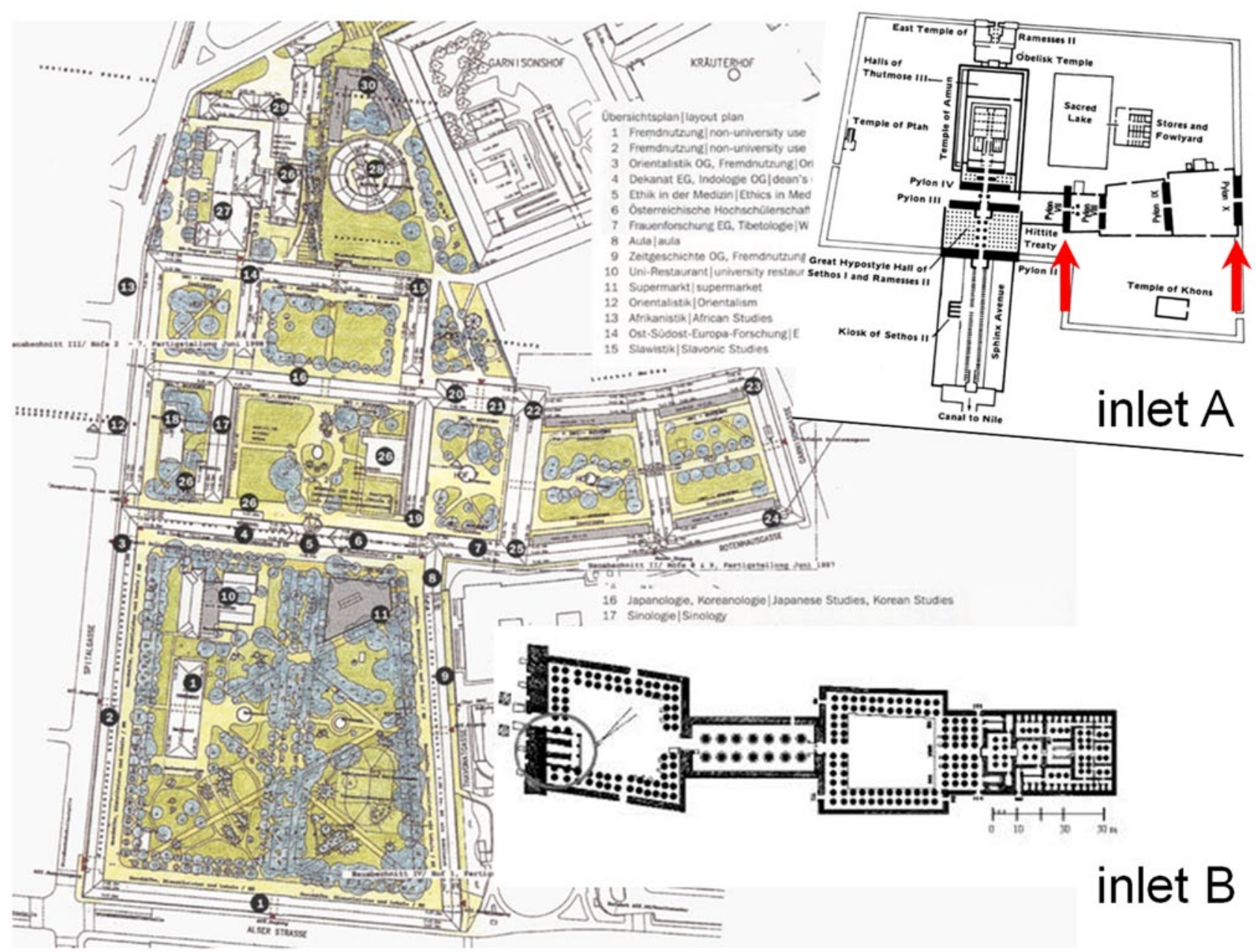

Fig. 4 The image compares the major axial ground plot orientation of the old Vienna General Hospital with that of the ancient Egyptian temples of Karnak (inlet $A$ ) and Luxor (inlet $B)$. As described in the text, the ground plot orientation of the old Vienna General Hospital incorporates that of the individual temples of Karnak AND Luxor, as well as that of the entire ensemble of the temple of Karnak plus the axis of its side pylons

what it is all about: the power of mood. Graduate students paste autistic lines into tablet phone industry manifestations to search out for a web-based Google stream spider of electronic emotion toward the lost dreamland of hope, security, and coziness. May a book be as good to replace a real face? Every face harbors the folds and eyes of a fascinating legacy of a long and deep going history of people, countries, and migrations. Maybe sugar is as good to snow upon a real mountain top? Maybe the truth is as good to replace a decision? This also counts for the common trunk surgery. Thereafter, you will fly, fly after power, money, and satisfaction of your self-esteem. But, be aware of the sun, it may burn the wings, the game will be over and you may have to fall, it will be a very deep fall. The higher you climb the deeper you fall. You may be one of the angels knowing that. Now you try to com- (distance between the two red arrows in inlet $A$ ). Thus, the architecture of the old Vienna General Hospital reveals ancient Egyptian semiotic legacy, as described in the text. (Sources: old akh http://www.zeininger.at/inhalt/ucaakh/UCAAKH-01. jpg; http://www.bible-history.com/past/temple_amun_karnak. html; http://de.slideshare.net/hommik/02vanaegiptuse-kunst)

pensate your lack limos of knowledge and expertise with rude copy-paste plagiarism to improve your economic increase. However, patients will find out the trick and see that you are cheating them! Brothers and sisters, watch your step! Only wise men took THEIR time to slowly pave the way from the top to the ground of the valley, where they drank from the fruits of the well. Before that, it took them many years to climb up to the top. What remains is the wisdom of wide overview. Therefore, stop plagiarism and try to live with humility and gratitude. Otherwise, the stolen lack limos stress will strike you down into metabolic imbalance with hypertension, diabetes, or cancer. Even our top gendered spit spider leg bite hypocrite oncologists know that there exists no effective chemotherapy against greed, envy, and hate. 


\section{Symphony No.5}

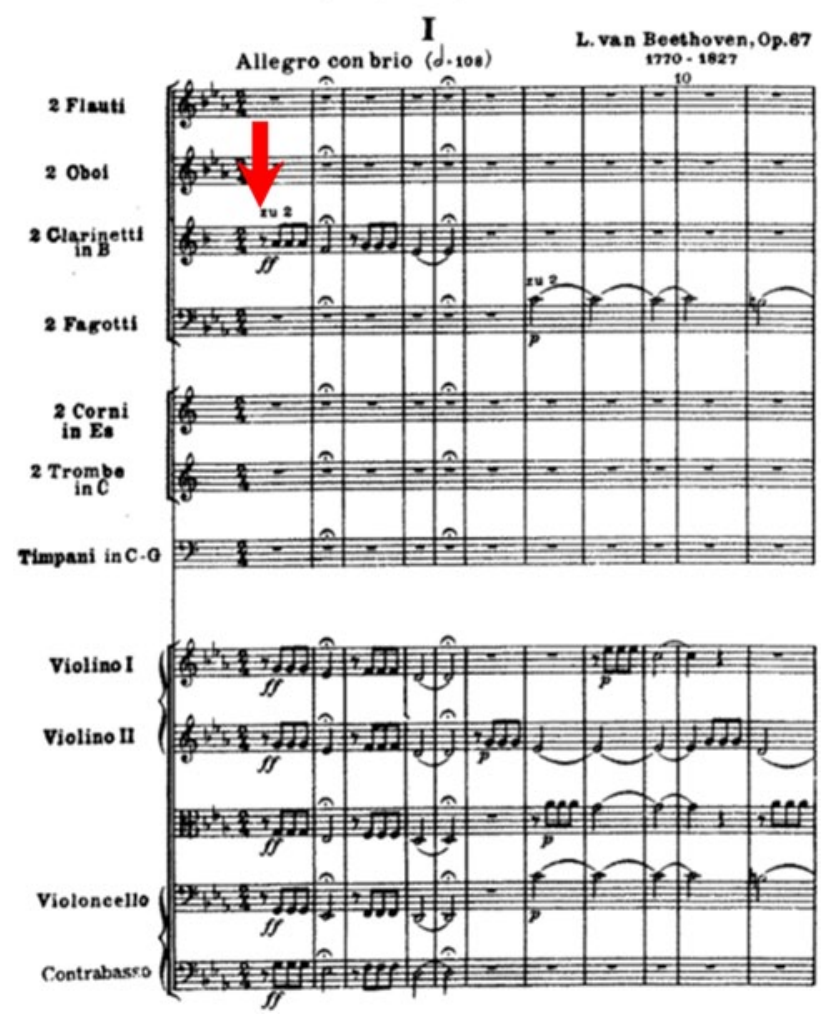

Fig. 5 Score of the beginning of the fifth symphony of Ludwig van Beethoven. Red arrow marks that the symphony starts with the absence of sound, i.e., a pause, as described in the text. The image mirrors the concept that lack limos is the essence and driving force for being, out of which perception arises, as described in the text. (Source: http://imslp.org/wiki/ Symphony_No.5,_Op.67_(Beethoven,_Ludwig_van))

\section{Power of symptoms}

Absence hides behind the positron curtain of electron ignorance in order to orchestrate perception streams of data. Please do not mind if fascinating statistics cannot replace the open-minded conduct of reasoning. However, the superficial approach to whatever it may be fosters pure reaction, biochemical messenger protein release from cold sweat extrusion toward closing the eyes for the essence. Energies work by offering a change. Basically and most importantly, it all remains the same: the song. Science takes medicine from what it has been before: from essence-based survival strategy understanding to superficial living room cuboid cavity design. Living, working, chilling, dining, lunching, enjoying, reproducing, vomiting, digesting, and existing in the shining atmosphere of a modern well-designed operation theater. Bridge the existence without knowing about the qualities of the colored river running below. Ringdriven energies order the universe into one and the other directions. Kepler does not only indicate the name of an underground tube station of the red line in the central peninsular European city of Vienna.
Power is limos (= deficit, lack) and cannot be seen [6]. As such, the person enters your office to become a patient. Following the for to go take away of the so-called patient history, you may be beverage tilted to hear: "Why doc, are you always asking me, when I do have my complaints, wouldn't it be much better to learn when I do not have my symptoms? This approach may turn you from being a manager of disease into being a manager of health and well-being!" Science draws the focus from the soul to the clinical study design data. Calculation rules and designs our modern world. Facebook fosters fulminant World Wide Web-frightened basis for the funeral. iPhone and YouTube tablets cannot be swallowed at once. The gullet does NOT take it all. Who fits the teeth for the bite? Who opens the window of close? Shut your mouth. Why run into the screen without knowing that the truth reveals that you are running into yourself without knowing it! What a shame! Try to be different, at least for a short period of space and time and states of energies. What remains is the power of mood. Here the clock strikes: one love, one people, one destiny, one faith, one hope, one ignorance, one tune, one power, unseen.

The record of symptoms equals a measurable size of sound, smell, and images to serve as a critical categorized content marker of a disease to justify diagnosis and therapy and thus justifies the economic, social, and network-based very special and focused existence of a given physician with and without a spectrum of fascinating machines, tools, blow holes, foods, and beverages (vinegar vegetarian green lands, roots people stone age muscle eaters, outbalanced carb diet, FX shit-out the gut underwater therapy, swim and save your life as long as you can). Why should we worry about air if we are not at all understanding the essence of water? Why it flows and nourishes? Drink the water and you may feel the messages it contains: millions of years of history diluted within a single fascinating drop of water! And here we go: the absence of symptoms equals health and is the end point of scientific reasoning and clinical study design. It remains to be questioned whether the focus on health instead of disease may be the start of an essential and outstanding and modern, unique reasoning? Here the patient peeps out a bird bubbling blues: "If you, dear reader, would be open to learn under which circumstances I do not perceive the symptoms, this could probably help you to take these information to foster the high-speed conduct of electron reasoning to dynamically develop a pluripotent beautiful therapy strategy to eliminate these symptoms in order to help me to regain life quality, productivity, and well-BEING," replies the pause to the physician. Electron dynamics foster the positron reasoning to uprise against the habit of ignorance. Well-being, what a being is that? Well-tuned, what tune is that? Well-powered, what mood is that? Open the file and click the OK button to read: all starts with the power of mood. This is you. And here starts YOUR world. Back to the patient: this in turn provides an alternative new sight toward the reign of matter and facts. Finally, it remains to be questioned whether such approach may contribute to 
Fig. 6 Score of the first bar of the fifth symphony of Gustav Mahler. Red arrow marks that the first notes of the symphony mirror the backward movement of the first motive of the fifth symphony of Ludwig van Beethoven (source: http:// lamb.cc/follow-the-score/ play/?score=/mahler/symphony/5\#). The image cartoons the idea that semiotic citations are connected to a deeper symbolism: limos hides to capture essence of being

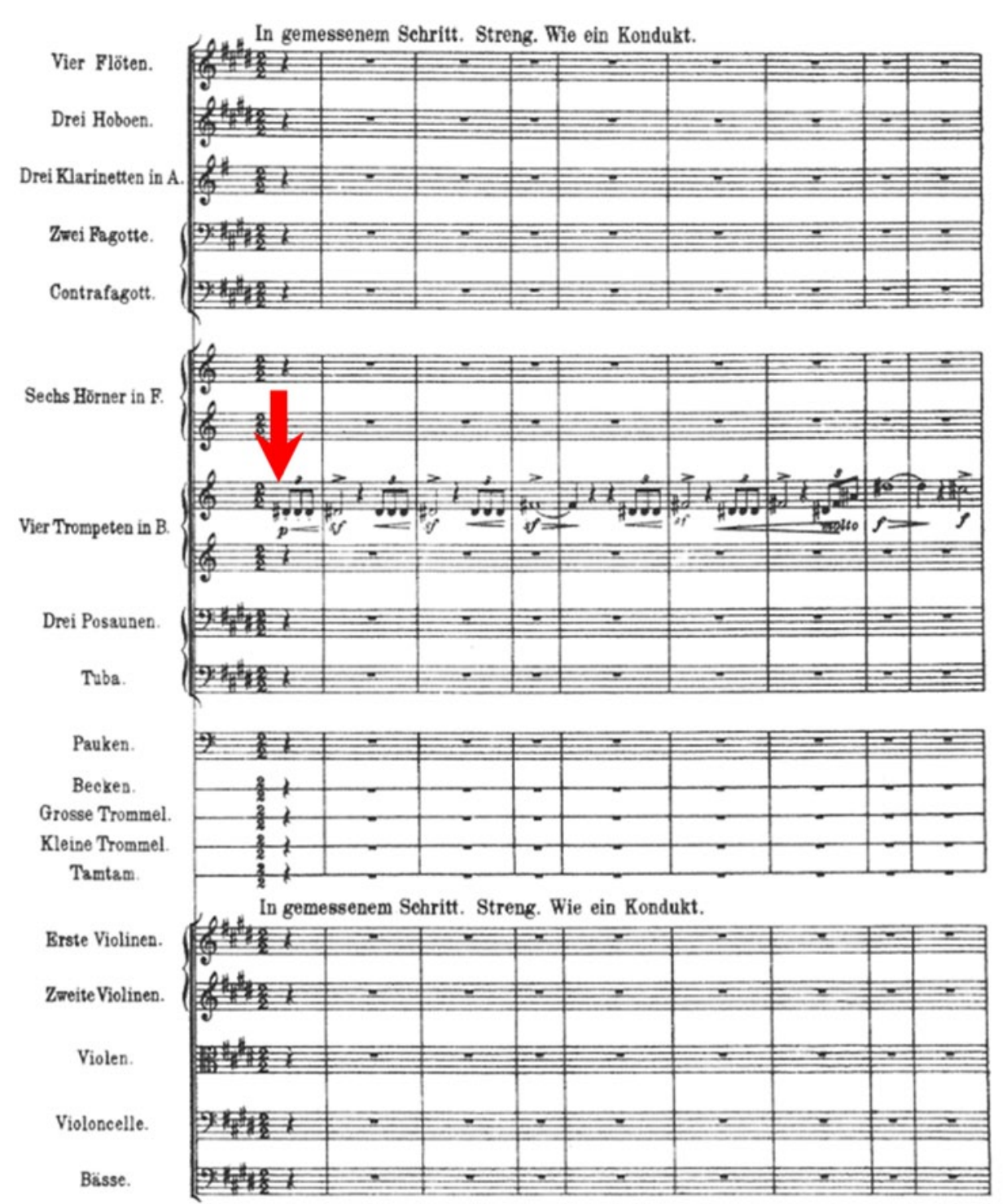

effective life style monitoring and health design. We are all out for the same, be it clouds, states, and fluctuations of electrons, positrons, dynamics, or hesitations (Fig. 2). Biopsies are taken out of the continuous stream of perceptions within a given tune of mood: state of art, hold on and out. Here we go.

\section{Power of signs}

Health systems are challenged to keep up with the needs and requirements of the present time, to keep up with the continuous change of demands. World changes life style, life style fosters new manifestations of diseases, and these in turn tune up the wide and large range of exploitation industries ranging from war fare and nutrition to medical industry share holder company wavers. Floods turn the sands and mirror a deep down premise: who comes first is served first and surely ends up in the first row at the cemetery.
Semiotic analysis of the architecture and round plot of a given city may allow a diagnosis of the state of mood of the inhabitants. Excel list-type towers harbor individuals as mean values and sums. Streets connect masters and slaves for exchange of data and borrowed possessions. Cities are organisms kept alive by their inhabitants. Pulsations of the daily business fluctuate through the streets, places, squares, and ways to specifically orchestrate the breathing atmosphere and tune. Optical and acoustic biopsies are slightly composed to form the film. The architecture of a city incorporates the legacy of signs and meaning of the very past and talks to those who open their minds, eyes, and reasoning to catch the tune. Thus, the architecture of the Medical University of Vienna makes it to be a very special place. The arrangement of the old Vienna General Hospital, being put into service on August 16th, 1784, by the Habsburg Kaiser Joseph II, incorporates in a cross-type fashion the ground plot and axial orientation of the ancient Egyptian temples in Karnak and Luxor (Fig. 4). Thus, the yards 1, 2, and 3 
Fig. 7 Score of the last bar of the fifth symphony of Gustav Mahler. Red arrow marks the pause finalizing the last bar of the symphony (source: http://lamb.cc/follow-thescore/play/?score=/mahler/ symphony/5\#). In contrast to that, the fifth symphony of Beethoven starts with a pause. The image cartoons the idea of backward movement citation of the fifth symphony of Beethoven within the fifth symphony of Gustav Mahler. This mirrors the idea that presence is already captured within absence before its appearance. Thus limos/ pause is considered to mirror the essence of being

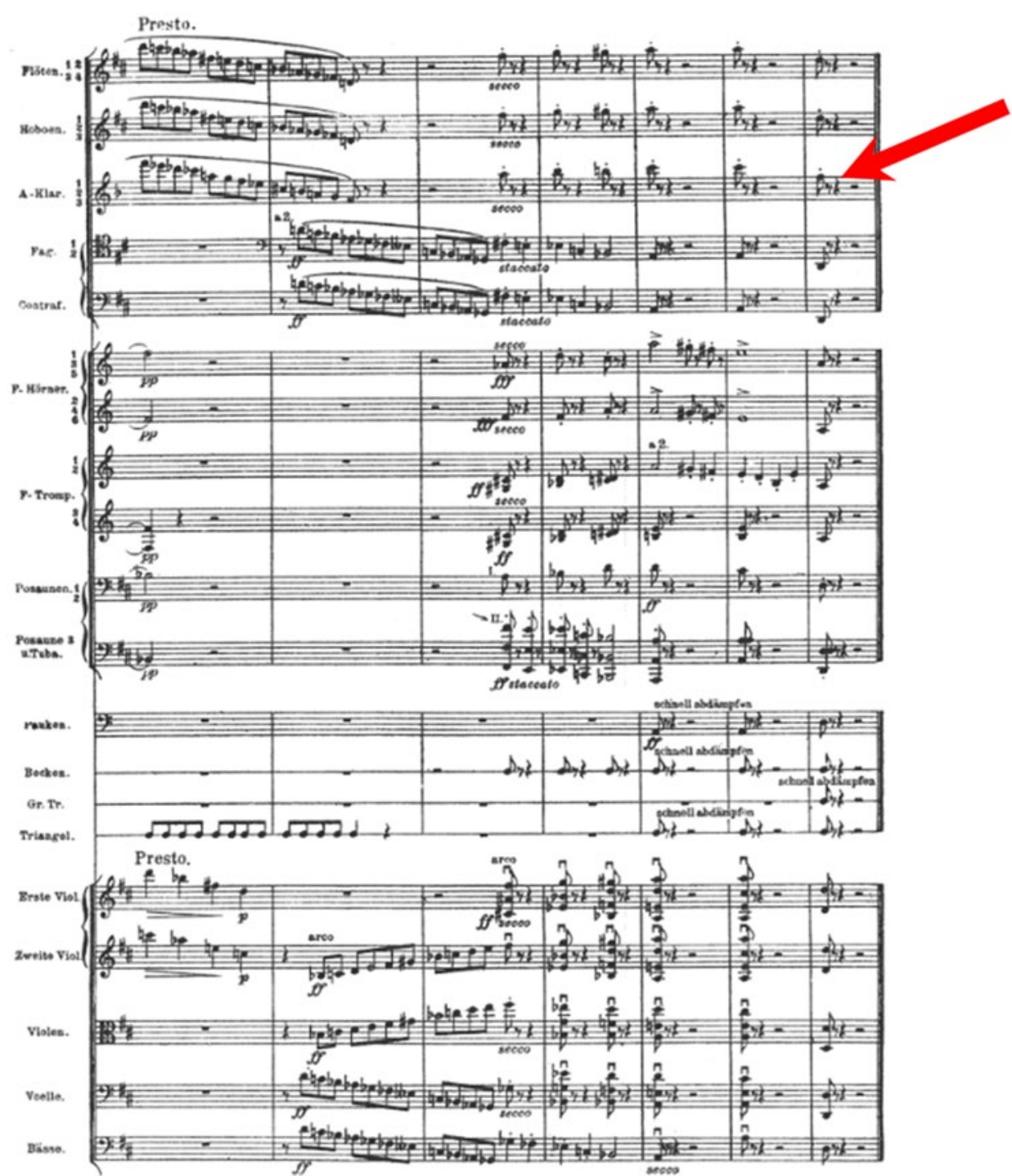

mirror the ground plot of the temple of Karnak; the orientation of the yards 7, 8, and 9 mirror the orientation of the temple of Luxor. In addition, the entire orientation of the old Vienna general hospital also mirrors the ground plot orientation of the temple of Karnak with its side pylons, the axis of which are mirrored by the orientation of yards 7, 8, and 9 (Fig. 4). In keeping with the semiotics of the ancient Egyptians temples, the ground plot of the old Vienna general hospital is oriented along the axis of the sun rise at the spring and autumn equinoxes and the winter and summer solstices. It remains to be questioned whether this just happened by chance. We will go back to that within the upcoming issues of European Surgery. Let us return to the year 2015.

Completing the holy number of seven, as the seventh hospital belonging to Vienna's town hall government, the modern sociomedical center north is in the process of erection. Maybe it is of specific meaning that the sociomedical center north stands opposite to the headquarter of the Siemens company, the architecture of which models the ark of Noah? What type of tide is going to come up? One full wave of metabolic disease to be treated within the modern hospital? A tide full of flimflam double-deal economic mix-up involving streams of money between political representatives and decision-making platforms regarding the electronic logistics and outfit of the new hospital? Or maybe it simply mirrors the present tide that is going to rush over the accident from the east? Right would be wrong, if the decision would have been drawn upon the course of the shadow of the sun thrown by stick positioned somewhere within the southern hemisphere of the globe. Orientation counts and matters for definition. The tide may also be an outbalanced mixture of all of the above options. Finally, who will survive the tide? Those living in the ark? Ancient Greek $\sigma \dot{\omega} \zeta \omega$, sozo = rescue. The question remains: who in this highly social scenario rescues whom from whom and what?

\section{Power of balance}

Every treatment requires a diagnosis. Every diagnosis starts with the take of the patient history. Once upon a time, there was no perception, and all the data obtained 
by those who felt they know physical examination led to fill the gap lack limos deficit with numbers, names, and prepositions. As the takeoff, the history starts, and physicians and nursing personnel usually focus on the symptoms [11]. However, how may the story go if the patients are asked to list situations and conditions with absence of the symptoms, where disease gaps out, lacking the limos? Most importantly, the fifth symphony of Ludwig van Beethoven starts with a pause (Fig. 5)! There is something that cannot be heard. Why did Beethoven let his symphony start with a pause? The absence of sound is the essence of his message! Limos pause absence gives birth to perception! Absence of symptoms mirrors the pause. Absence of sound mirrors lack limos. And this limos is consequently spilled out into the score, as the limos attracts the tune out of the brain of the composer into the lines of the score. In between, we may or may not sense the magical power of mood. And Gustav Mahler turned it all around in the beginning of his fifth symphony. He lets the symphony start with a reverse, backward movement of the melodic figure of the starting motive of the fifth symphony of Ludwig van Beethoven (red arrow in Fig. 6) and puts the pause at the end of his symphony (red arrow in Fig. 7). Thus, the fifth symphony of Gustav Mahler represents a backward movement citation of the fifth symphony of Ludwig van Beethoven most importantly playing with the symbolism of motives and pause. With the pause at the end, Mahler directly connects his fifth symphony to the start of the fifth symphony of Beethoven and aims to symbolize the close of ring of desire. There is no doubt that this all has a very deep semiotic meaning. Here the power of limos decided to speak to us through the minds of these great composers to take our history. They put us into question, as we were the pause? Thus evokes the harmonic power of balance between pause, pick up, and rubber dub doubling sound. There you find the gathering gate to health.

\section{Power of final}

Dear reader, let us open for the power of pause. Let us allow a break to consider and think: what covers hides, what bridges connects and holds out the bridged. The meaning of pause, the meaning of absence, deficit lack limos gap? Do all models and concepts start out with a no, absence, and lack? Does it all originate out of a lack logos absence of perception? Being as the lack of limos? Here we go and foster a new thought out of the pause. Let us follow the track of Ludwig van Beethoven; the pause offers initiation to bring into order the electrons, positrons, dynamics, and energies to get ready for the upcoming stream of mood manifestation. Out of the pause mirrors and models' understanding. Lack limos lingerie orchestrates the power of mood. Stay tuned and mind that patients wish to be cut only after having defined their health. Pause and enjoy the perceptions fostering the hormonal changes of YOUR spring. Do not be afraid of yourself. Be open for the legacy of the power of mood.

\section{Acknowledgments}

The author thanks "limos," his family, friends, colleagues, and patients, who profoundly contribute to develop and maintain the conduct of open-minded humilitybased reasoning, as outlined in the editorial. Furthermore, the author thanks the musician, composer, piano, organ player, choir master, and conductor Mag. Thomas Holmesfor his deep friendship, musical education, and the opportunities to share the semiotics of music outlined within the text. May the author's suggestions stimulate others to bring it to perfection, value, and shine for the beneficial orchestration of our beautiful globe.

\section{Conflict of interest}

The author declares that there exists no conflict of interest.

\section{References}

1. Simic AP, Skrobic OM, Velickovic D, et al. Minimally invasive surgery for benign esophageal disorders: first 200 cases. Eur Surg. 2015;47.

2. Novotny R, Hruby J, Hlubocky J, et al. Giant paratracheal ancient schwannoma in 57 year old male patient case report. Eur Surg. 2015;47.

3. Ikeguchi M, Amisaki M, Murakami Y, et al. Differences in quality of surgery for advanced gastric cancer between institutions. Eur Surg. 2015;47.

4. Simic AP, Skrobic OM, Djuric-Stefanovic A, et al. From Ockham's razor to Hickham's dictum and back-Saint's theory and the insights in herniosis. Eur Surg. 2015;47.

5. Schoppmann SF. Reflux multidiziplinär. June 12, 2015. Infos via: www.meduniwien.ac.at/upper-gi, www.gast.at; registration (free): anmeldung@gastx.at.

6. Riegler MF. The lemon taste of limos. Eur Surg. 2014;46:99-102.

7. Riegler MF. Surgery today: smile clears the tide. Eur Surg. 2014;46:227-30.

8. Leakey RE. Origins. New York: Plume; 1979.

9. Europe. http://en.wikipedia.org/wiki/Europe.

10. Miller G. Moon shine serenade. https://www.youtube. $\mathrm{com} /$ watch? $\mathrm{v}=\mathrm{AQseFAcWvtE}$

11. Riegler MF. Essence-based surgery: a taste for fruitful reasoning. Eur Surg. 2014;46:49-51. 